\title{
Voltage Regulation of Hydro Standalone 1- $\Phi$ Micro Grid using Fuzzy Logic Based Adaptive Sliding Mode Control Algorithm
}

\author{
Ramya Vasamsetti, S. Varalakshmi, M. Mangalakshmi
}

\begin{abstract}
This paper presents an adaptive sliding mode control (ASMC) of an improved power quality standalone single phase microgrid system. The proposed microgrid system integrates a governor-less micro-hydro turbine driven single- phase two winding self-excited induction generator (SEIG) with a wind driven permanent magnet brushless DC (PMBLDC) generator, solar photo-voltaic (PV) array and a battery energy storage system (BESS). These renewable energy sources are integrated using only one single-phase voltage source converter (VSC). The ASMC based control algorithm is used to estimate the reference source current which controls the single-phase VSC and regulates the voltage and frequency of the microgrid in addition to harmonics current mitigation. The proposed ASMC estimates the reference real and reactive powers of the system, which is adaptive to the fluctuating loads. The sliding mode control is used to estimate the reference real power of the system to maintain the energy balance among wind, micro-hydro, solar PV power and BESS, which controls the frequency of standalone microgrid. The proposed microgrid is implemented in real time using a DSP (Digital Signal Processor) controller. Test results of proposed microgrid shows that the grid voltage and frequency are maintained constant while the system is following a sudden change in loads and under intermittent penetration of wind and solar energy sources.
\end{abstract}

Index Terms: Standalone Microgrid, Renewable Energy Source, Single Phase SEIG, Battery Energy Storage System (BESS).

\section{INTRODUCTION}

HE benefits of an integration of renewable energy sources like wind, solar and micro-hydro with BESS (Battery Energy Storage System) are currently well recognized. The function of microgrid as controlled entities explores the possibility of coordinating standalone renewable energy sources so that they behave as a single producer of electrical energy to avail the full advantages of renewable energyresources in a consistent and manageable way.The energy balance and system parameters control are the key features of the microgrid.In order to achieve proper integration of renewable energy sources (RES),

Revised Manuscript Received on December 25, 2020.

* Correspondence Author

Mrs.Ramya Vasamsetti*, Department of Electrical and Electronics Engineering, Pragati Engineering College, Surampalem, Peddapuram. Electrical and Electronics Engineering in Pragati Engineering College, Surampalem, Peddapuram.

Mrs. M.Manga Lakshmi, Assistant Professor in the Department of Electrical and Electronics Engineering College in Pragati Engineering College, Surampalem, Peddapuram.

(C) The Authors. Published by Blue Eyes Intelligence Engineering and Sciences Publication (BEIESP). This is an open access article under the CC BY-NC-ND license (http://creativecommons.org/licenses/by-nc-nd/4.0/)
Ms. S.Varalakshmi, Assistant Professor in the Department of

the development of effective frequency and voltage control scheme is essentially desired [1] - [2]. The concept of microgrid is most interesting for successful dealing with the challenges in the integration of renewable energy sources [3]. A microgrid is having capability to operate in both standalone and grid tied modes operation depending upon the design of suitable control scheme [9] - [10]. The various derived forms of the microgrid such that virtual power plant, cognitive microgrid and active distribution system can be studied as a main constituent of smart grid [4] - [8]. In grid tied microgrid, the main grid supplies the deficit power and absorbs the surplus power in a grid tied microgrid in order to maintain power balance which in turn regulates the system frequency. Whereas, in a standalone microgrid, the balance of active and imaginary powers, is achieved using controlling the flow of power among different components of the microgrid[9] - [10]. An IEEE standard for interconnection of distributed energy sources are given in [11]. The voltage, frequency, real and imaginary powers are the main system variables required to control the operation of the microgrid [11]. BESS allows the large scale integration of intermittent energy sources [12]. Despite of its benefits, the capacity of BESS is not fully utilized in the microgrid system yet [13]. Power electronic control of integrated renewable systems has been discussed extensively in [14] - [15]. A comprehensive review of control of power electronic converters used in microgrid is presented in [16]. The main challenge in control of standalone microgrid includes the balance of powers and control of system voltage [17]. NABC and other control schemes of single-phase SEIG feeding fluctuating loads is reported in [18-22]. The comparison among photovoltaic array maximum power point tracking techniques are discussed in [23]. In this paper, the design and implementation of an adaptive sliding mode control (ASMC) algorithm [24] of single-phase microgrid system is proposed. It consists of three main renewable energy sources such as micro-hydro, wind and solar PV based generation.

- The main contributions and advantages of proposed system are as follows.

The adaptive sliding mode control (ASMC) eliminates all possibilities of overshoot and undershoot problem in DC link voltage of the VSC which reduces the required size of DC link capacitor and BESS. The proposed control reduces the size required for DC link capacitor connected across the BESS.

Published By:

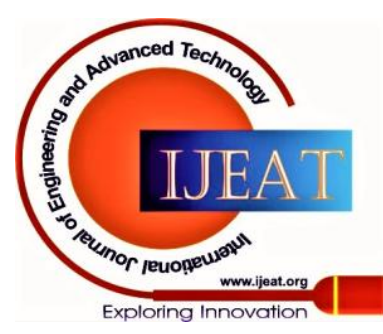




\section{Voltage Regulation of Hydro Standalone 1- $\Phi$ Micro Grid using Fuzzy Logic Based Adaptive Sliding Mode Control Algorithm}

The proposed control never allows the increase of DC link voltage above the maximum float charge voltage that increases the life of the battery. The proposed sliding mode based control used for power balance is found highly suitable, stable and robust for such highly nonlinear microgrid system where the multiple parameters vary in a very large range. The ASMC algorithm provides a robust and adaptive control of system frequency and voltage with good dynamic and steady state response, which is the main requirement of a good standalone microgrid as reported by IEEE-PES Task Force on microgrid control in [17]. The reported single-phase SEIG is investigated by many researchers for bio energy and small hydro driven systems but the benefits of this machine are not fully exploited for microgrid system (fearing the complications of nonlinear relationship in frequency, magnetizing reactance and speed of single phase SEIG). SEIGs have many advantages over other generators, like simple, brushless, low unit cost, low maintenance, high power/weight ratio, absence of DC excitation etc.In the proposed system the governor-less control of small hydro uncontrolled turbine driven SEIG and wind driven PMBLDC generators, reduces the overall cost and size of the generators significantly. It also makes the system frequency independent of the mechanical inertia of turbine generator.The proposed single-phase microgrid integrates the renewable energy sources of low power capacities for their optimum utilization. The capacity of a BESS required to handle surplus generated power is also reduced by integrating various renewable energy sources. The reliability of the system is improved by integrating various low power renewable energy sources, as it is the main limiting factor in utilizing low power renewable energy sources. The reliability is further improved by adding the BESS. The cost of the BESS becomes the main issue while it is used as separately for each individual renewable energy sources like solar PV-array, micro-hydro and wind based generation to improve the reliability of individual system. The total required capacity of the BESS is significantly reduced using proposed standalone singlephase microgrid system. The proposed control algorithm regulates the system voltage and frequency, mitigates harmonics current, ensures maximum utilization of BESS capacity and also integrates the various small renewable energy sources. Whenever, the dynamic situation arises (e.g. variation in loads, wind speed or insolation level of solar radiation), the proposed control algorithm maintains the power balance by shifting the load among three generating systems even if it is not possible to achieve power balance, wherein only the BESS comes into action. Thus, the capacity of BESS is optimally utilized. The BESS is used for frequency control instead of speed governor at the small hydro turbine in order to make the system frequency independent of the mechanical inertia of turbine generator. The proposed microgrid is suitable for low power generation using hydro, wind and solar energy to cater to modern nonlinear loads.

\section{SYSTEM CONFIGURATION AND OPERATING PRINCIPLE}

The block diagram of proposed single-phase microgrid is depicted in Fig. 1. This microgrid consists of an unregulated

micro-hydro turbine driven single-phase two winding SEIG (Self-Excited Induction Generator), a wind turbine driven PMBLDC (Permanent Magnet Brushless DC) generator, solar PV (Photovoltaic) array and a BESS. Conceptually, the single- phase SEIG is only the AC generating source in this microgrid, which directly caters the load whereas remaining two generating sources are connected to the load through a voltage source converter (VSC). It converts the DC power generated by PMBLDC generator and solar PV array into AC power when the power generated from SEIG is less than the load. The solar PV-array, wind turbine driven PMBLDC generator and BESS are connected at the DC bus of the VSC.

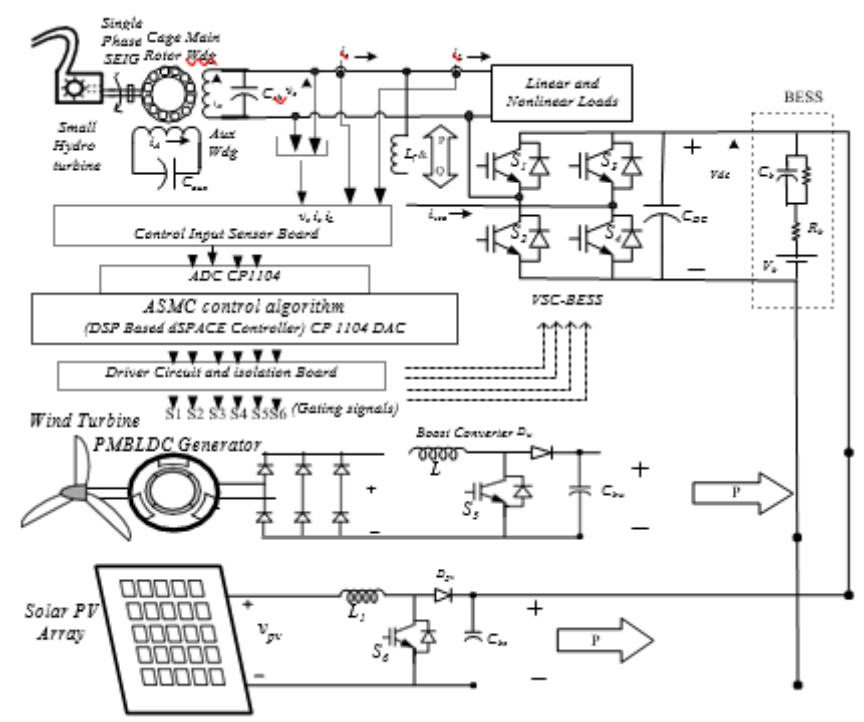

Fig. 1 System configuration of the single-phase microgrid

All these three energy sources supply only the real power to the system. They do not participate in any reactive power transaction with the system. When the total real power generated by the SEIG, PMBLDC generator and solar PVarray is less than the load, then the BESS compensates the additional real power demand of the load. The VSC converts the DC power supplied by the BESS into the AC power to make it suitable for single-phase load connected at AC side of microgrid. In the alternate case, the surplus energy is stored in the BESS to maintain the power balance. Under variable load conditions, single-phase SEIG and the load need adjustable harmonics and reactive power to maintain the microgrid AC voltage at rated value. The VSC is controlled using a DSP (Digital Signal Processor) to compensate this adjustable reactive power demand of the system. The VSC also compensates the real power need of the loads.

\section{CONTROL ALGORITHM FOR VSC-BESS OF MICROGRID}

An adaptive sliding mode control (ASMC) based algorithm is developed to estimate the reference source current and switching pattern for VSC of microgrid.

Published By:

Blue Eyes Intelligence Engineering and Sciences Publication

(C) Copyright: All rights reserved.

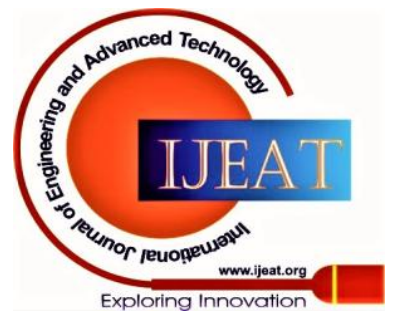


The block diagram of proposed ASMC algorithm is shown in Fig. 2. It is well known that the SEIG system requires an adjustable reactive power under varying load conditions to maintain the PCC voltage at reference value. The amplitude of terminal voltage of the single-phase SEIG is estimated as,

$$
V_{t}=\sqrt{v_{p}{ }^{2}+v_{q}^{2}}
$$

where vp and vq are the in-phase and quadrature constituents of the microgrid AC voltage (or SEIG output voltage). The quadrature constituent of microgrid AC voltage is estimated and generated using frequency estimation and phase shifting (FEPS) block [18]. The microgrid AC voltage may be expressed as,

$$
\begin{aligned}
& v_{q}=V_{t} \sin \omega t \\
& v_{q}=V_{t} \cos \omega t
\end{aligned}
$$

Where vp is the instantaneous $\mathrm{AC}$ voltage, $\mathrm{Vt}$ is the amplitude and $\omega$ is the angular frequency of the microgrid AC voltage. The in-phase and quadrature unit templates of microgrid AC voltage are derived as,

$$
\begin{aligned}
& u={ }^{v} q \quad \text { and } u={ }^{v} p \\
& q \overline{V_{*}} \quad p \overline{V^{\prime}}
\end{aligned}
$$

The in-phase part of reference source current is responsible for frequency control of the system and power balance among SEIG, PMBLDC generator, solar PV-array, battery and the load. In proposed ASMC control algorithm, an adaptive filter is used to extract the amplitude of fundamental active and reactive power constituents of load current. The proposed control algorithm is a combination of two control loops. First loop controls its voltage by injecting an adjustable reactive power and other loop maintains active power balance among various energy elements in the microgrid.

\section{A. Estimation of In-Phase Part of Reference Source Current}

The ASMC extracts active power part of load current as follows. If the in-phase unit template (per unit value) of microgrid AC voltage, up(t) and harmonic current component, ih(t) have equal frequency, then Mp1multipliers output (Xp) consists of direct and alternative current (DC and AC) components. The output of multiplier is fed to the integrator which filters the alternating component and integrates the DC component to estimate the gradually increasing real power weight component of load current $\mathrm{Wp}(\mathrm{t})$.The output of an integrator is fed to another Mp2 multiplier of same (upper) branch, which multiplies the weight component $\mathrm{Wp}(\mathrm{t})$ with in phase unit template of microgrid AC voltage up(t). It gives fundamental real power component of load current $i \operatorname{Lpf}(\mathrm{t})$. The harmonic constituent of load current ih at kth sampling instant can be acquired by subtracting fundamental constituent of load current iLf from its instantaneous value.

$$
i_{h}(k)=i_{L}(k)-i_{L f}(k)
$$

The fundamental constituent of load current is calculated as,

$$
i_{L f}(k)=i_{L p f}(k)+i_{L q f}(k)
$$

where $i_{L p f}(k)$ and $i_{L q f}(k)$ are the fundamental real and reactive power constituents of load current respectively. $i_{\text {Lpf }}(k)$ and $i_{L q f}(k)$ are outputs of the multipliers $M_{p 2}$ and $M_{q 2}$ respectively. The $M_{p 1}$ multiplier's output $X_{p}$ at $k^{\text {th }}$ sampling instant is as,

$$
X_{p}(k)={ }^{\mu} p(k) i{ }_{h}(k)
$$

The output of the multiplier $M_{p 1}$ consists of a direct as well as alternating constituent when the in-phase unit templates of microgrid AC voltage $u_{p}(k)$ and harmonic constituent $i_{h}(k)$ have the equal frequency. The output of integrator $I_{p}$ at $(k+1)^{t h}$ sampling instant is estimated as,

$$
W_{p}(k+1)=W_{p}(k)+A u_{p}(k) i_{h}(k)
$$

where $W_{p}(k+1)$ and $W_{p}(k)$ are the outputs of integrator $I_{p}$ at $(k+1)^{\text {th }}$ and $k^{\text {th }}$ sampling instants.

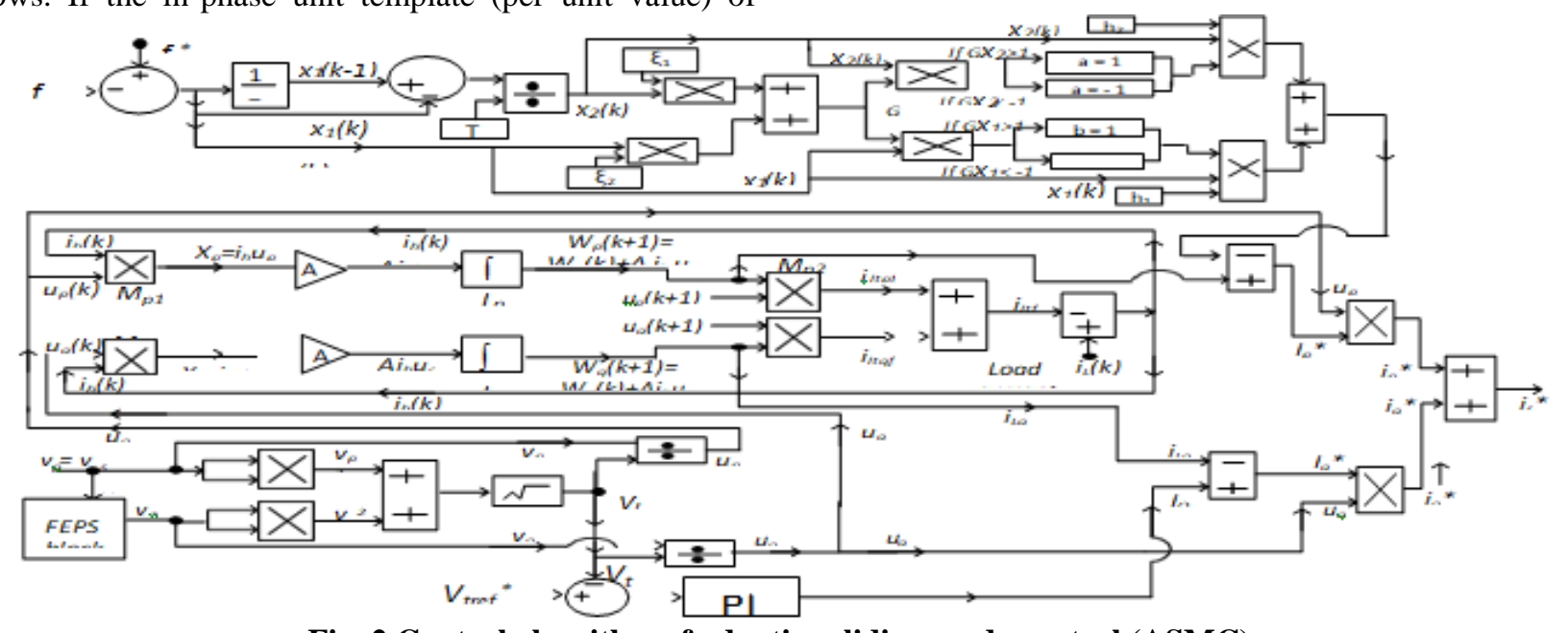

Fig. 2 Control algorithm of adaptive sliding mode control (ASMC)

The integrator eliminates the alternating constituents from the output of $M_{p 1}$ multipliers $\left(X_{p}\right)$ and integrates the direct constituent to calculate the real power weight component of load current $W_{p}(t)$.The output of integrator $I_{p}$ at $(k+1)^{\text {th }}$ sampling instant is calculated as,

$W_{v}(k+1)=W_{v}(k)+A u_{v}(k)\left\{i_{L}(k)-i_{L v f}(k)-i_{L a f}(k)\right\}$ when $W_{p}(k)$ is positive, the current $i_{L p f}(k)$ remains in phase with the in-phase unit template of the microgrid AC voltage $u_{p}(k)$ and when calculated weight $W_{p}(k)$ is negative, the $i_{\text {Lpf }}(k)$ is opposite in phase with the $u_{p}(k)$.

Published By:

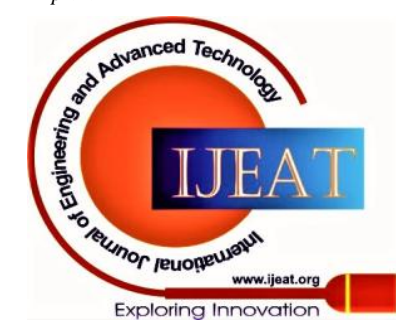




\section{Voltage Regulation of Hydro Standalone 1- $\Phi$ Micro Grid using Fuzzy Logic Based Adaptive Sliding Mode Control Algorithm}

In steady state condition, when the harmonics are completely eliminated the weight $W_{p}(k)$ becomes a constant value. The error in system frequency at $k^{\text {th }}$ sampling instant

$$
x_{f}(k)=f^{*}(k)-f(k)
$$

where $f^{*}(k)$ is reference frequency and $f$ is system frequency. The derivative of system frequency error is calculated as,

$$
\dot{x}_{1}=x_{2}(k)=\frac{1}{T}\left\{x_{1}(k)-x_{1}(k-1)\right\}
$$

$x_{2}(k)$ is the derivative of the system frequency error signal $x_{1}(k)$. Where $x_{1}$ and $x_{2}$ are the state variable of the system and $T$ is the sampling interval.

The switching hyperplane function of the frequency loop of the ASMC algorithm is given as,

$$
G=\zeta_{1} x_{1}+\zeta_{2} x_{2}
$$

where $\zeta_{1}$ and $\zeta_{2}$ are the gain constants of switching hyperplane function of the frequency loop. $G$ is a switching hyperplane function on the locus of active power constituent of the load and $1 / \mathrm{Z}$ represents a unit delay.

The switching function is defined as,

$$
\begin{array}{ll}
a=+1 & \text { if } G x_{1}>0 \\
a=-1 & \text { if } G x_{1}<0 \\
b=+1 & \text { if } G x_{2}>0 \\
b=-1 & \text { if } G x_{2}<0
\end{array}
$$

In addition to real power weight component of load current $W_{p}(t)$, the power balance constituent $\left(P_{b a l}\right)$ is estimated. The power balance constituent $\left(P_{b a l}\right)$ needed to control the system frequency at reference value, is estimated as follows.

$$
P_{b a l}(k)=h_{1} x_{1} a+h_{2} x_{2} b
$$

where $h_{1}$ and $h_{2}$ are the gain constants of ASMC.

The amplitude of the real power constituent of the reference AC source current $I^{*}$ is estimated as,

$$
I_{p}{ }^{*}=P_{b a l}-W_{v}
$$

The instantaneous active power constituent of referencesource current is estimated as,

$$
i_{f}{ }^{*}=I_{p}^{p} *^{*} u_{s}^{p}
$$

\section{B. Estimation of Quadrature Part of Reference Source} Current

The $M_{q 1}$ multiplier's output $X_{q}$ at $k^{\text {th }}$ sampling instant is as,

$$
X_{a}(k)=u_{a}(k) i_{L_{l}}(k)
$$

constituent $i_{h}(k)$ are having equal frequency. The output of the $M_{q 1}$ multiplier is fed to the integrator $I_{q}$. The output of integrator $I_{q}$ at $(k+1)^{\text {th }}$ sampling instant is estimated as,

$$
W_{a}(k+1)=W_{a}(k)+A u_{a}(k) j_{k}(k)
$$

where $W_{q}(k+1)$ and $W_{q}(k)$ are the outputs of integrator $I_{q}$ at $(k+1)^{\text {th }}$ and $k^{\text {th }}$ sampling instants.

The integrator eliminates the alternating constituents from the output of multiplier $M_{q 1}$ and integrates the direct constituent to estimate the value of quadrature weight component of load current $W_{q}(k)$

The output of integrator $\left(I_{q}\right)$ in the lower branch of ASMC at $(k+1)^{\text {th }}$ sampling instant is,

$$
W_{q}(k+1)=W_{q}(k)+A u_{q}(k)\left\{i_{L}(k)-i_{L p f}(k)-i_{L q f}(k)\right\}
$$

The voltage error in microgrid AC voltage at $k^{\text {th }}$ sampling is estimated as,

instant is given as,

$$
V_{\text {ter }}(k)=V_{\text {tref }}{ }^{*}(k)-V_{t}(k)
$$

The voltage error $V_{t e r}$ is calculated using (18) is processed in a PI controller used to control the microgrid AC voltage.

The output of PI controller at $k^{\text {th }}$ sampling instant is as,

$$
I \underline{Q}(k)=I \underline{Q}(k+1)+k_{p b}\left\{V_{\text {terr }}(k)-V_{t e r}(k-1)\right\}+k_{i b} V_{\text {ter }}(k)
$$

where $k_{p b}$ and $k_{i b}$ are the proportional and integral gain constants of the PI controller employed for microgrid AC voltage control. $V_{\text {ter }}(k)$ and $V_{\text {ter }}(k-1)$ are the signals

representing the voltage errors at $k^{\text {th }}$ and $(k-1)^{\text {th }}$ sampling instants. $I_{Q}(k)$ and $I_{Q}(k-1)$ denote the reactive current to be supplied by the VSC at $k^{\text {th }}$ and $(k-1)^{\text {th }}$ instant to compensate the reactive power demand of SEIG and load in order to maintain the microgrid AC voltage at reference value.

The amplitude of reactive power constituent of reference source current is estimated as,

$I_{\alpha}^{*}=I_{o}-W_{*}$

The reactive power constituent of reference source current is calculated as,

$i_{4}^{*}=I_{4}^{*} *_{4}$

\section{Estimation of Total Reference Source Current}

The total feferefice control current $\left(i^{*}\right)$ is estimated as,

$$
i^{*}=i_{p}^{*}+i^{*}
$$

This reference control current $\left(i^{*}\right)$ is compared with sensed source current (is) to calculate the current error constituent as, source current is estimated as,

$$
i_{\text {ser }}=i_{\xi}^{*}-i_{s}
$$

This current error is fed to a hysteresis PWM controller to generate the switching pulses to control the operation of VSC. The perturb and observe ( $\mathrm{P} \& \mathrm{O}$ ) control algorithm [19] is used for sensorless control for MPPT of PMBLDC

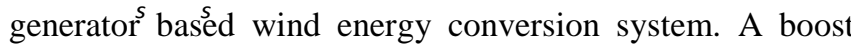
converter is connected at the output of diode bridge rectifier. This converter is controlled using $\mathrm{P} \& \mathrm{O}$ algorithm to extract The output of the Mq1 multiplier $(\mathrm{Xq})$ consists of a direct as well as alternating constituent when the in-phase unit templates of microgrid AC voltage uq(k) and harmonic maximum power from the wind generating system. An incremental conductance based control algorithm is used to extract maximum power generated from solar PV array [19].

\section{RESULTS AND DISCUSSION}

This section presents test results demonstrating steady state and dynamic performances of a developed prototype of microgrid.

\section{A. Steady State Performance of Proposed Microgrid} System

Test results of steady state performance of proposed microgrid are shown in Figs. 3 and 4.

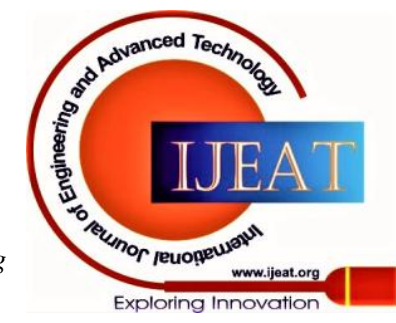


1) Steady State Performance of System When Total Generated Power by all Renewable Sources is More Than Load Power

Figs. 3(a) to 3(g) show that the total power generated (5.686 $\mathrm{kW}$ ) from all renewable sources (SEIG, PMBLDC generator and solar PV-array) is more than the load (4.81 kW). Therefore, the surplus generated power is stored into the BESS as shown in Fig. 3(e).

Fig. 3(a) demonstrates the waveforms of the SEIG voltage and current along with their crest factors. It shows that the SEIG is supplying almost sinusoidal current. The power generated by the single-phase SEIG is shown in Fig. 3(b). The SEIG is generating $3.88 \mathrm{~kW}$ power. It is less than the load of $4.81 \mathrm{~kW}$, as shown in Fig. 3(d). To compensate the additional real power demand of the load, remaining real power is supplied by the wind based PMBLDC generator and solar PV-array through VSC. Fig. 3(c) shows that VSC is feeding $0.92 \mathrm{~kW}$ of real power to the load. Fig. 3(d) demonstrates the load power and its power factor. The PMBLDC based wind generator and solar PV- array are supplying $0.92 \mathrm{~kW}$ power to AC side (to the load side) through VSC to compensate the remaining real power demand of the load $(0.92 \mathrm{~kW})$. The VSC converts the DC power generated by the remaining two renewable energy sources (solar PV-array and wind driven PMBLDC generator) into adjustable single-phase AC power when the SEIG output power is not sufficient to meet the power demand of the load. The power generated by wind driven PMBLDC generator and solar PV-array are demonstrated in Figs. 3(f) and 3(g) respectively. The PMBLDC generator and solar PV-array generate total $1.806 \mathrm{~kW}$ real power. Out of this $1.806 \mathrm{~kW}$ power, $0.92 \mathrm{~kW}$ power is fed to the load through the VSC,

$0.538 \mathrm{~kW}$ power is supplied to charge the BESS and remaining power is used to feed the loss constituent of VSC. When the SEIG output power is less than or equal to the power demanded by the load, the power generated from the SEIG is directly fed to the load without any interference of the VSC. If the power demanded by the load is less than the power generated by the SEIG than the surplus generated power is converted into the DC power using VSC and stored into the BESS. Figs. 3(a) to 3(g) show the power balancing ability of the proposed control algorithm. The proposed algorithm controls the VSC such that it balances the flow of power among the various energy sources (SEIG, PMBLDC generator, solar PV-array and BESS), which in turn controls the frequency of the microgrid system. The VSC supplies $2.4 \mathrm{kVA}$ of the fundamental and harmonic reactive power in order to maintain constant voltage and to mitigate the harmonic currents injected due to nonlinear loads. In addition to other multiple functions, the VSC is improving power quality and power factor. Fig.3 (i) demonstrates the SEIG output voltage and VSC current. Fig.3 (j) shows the SEIG output voltage and PMBLDC generator current. The harmonic spectrum and THD of the SEIG output current shown in Fig. 3(k) indicates a THD of $4 \%$, while it is feeding a highly nonlinear load current of $31.9 \%$ THD as shown in Fig. 3(l).

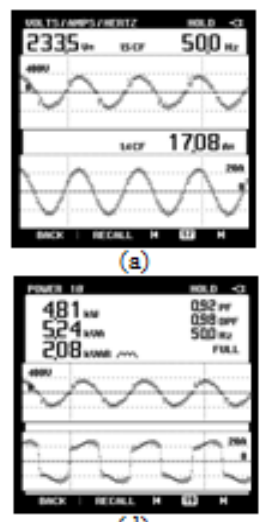

(d)

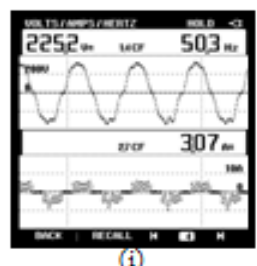

(i)
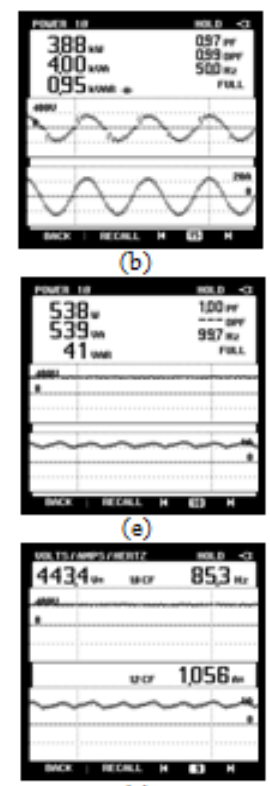

(g)

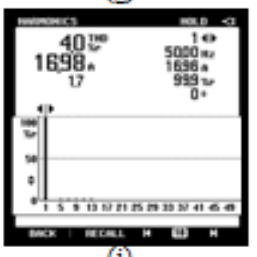

(j)
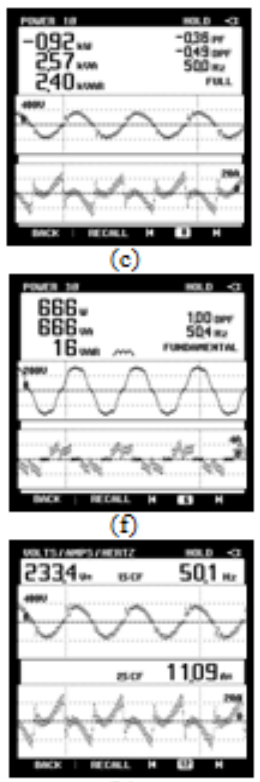

(h)

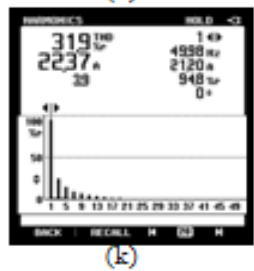

Fig. 3 Steady state performance of system when total generated power by all renewable sources (SEIG, PMBLDC generator and solar PV-array) is more than load

It proves the harmonics mitigation ability of proposed control algorithm as it is satisfying an IEEE 519 standard of the power quality.

1) Steady State Performance of System When Total Generated Power by All Renewable Sources is Less Than Load

Figs. 4(a) to 4(g) show that the total power generated $(5.716 \mathrm{~kW})$ from all renewable sources (SEIG, PMBLDC generator and PV array) is less than the load $(6.17 \mathrm{~kW})$. Therefore, an additional real power is supplied by the BESS through VSC, as shown in Fig. 4(e). Fig. 4(a) demonstrates the waveforms of the SEIG output voltage and current along with their crest factors. It shows that the SEIG is supplying almost sinusoidal current. The power generated from the single-phase SEIG is shown in Fig. 4(b). The SEIG is generating $3.91 \mathrm{~kW}$ power. It is less than the load power of $6.17 \mathrm{~kW}$, as shown in Figs. 4(b) and 4(g). To compensate the additional real power demand of the load, remaining real power is supplied by the wind based PMBLDC generator, BESS and solar PV-array through VSC. Fig. 4(e) shows that the VSC is feeding $2.24 \mathrm{~kW}$ real power to the load. Fig. 4(g) demonstrates the load power and its power factor. It is observed from Figs. 4(b) to 4(g), that SEIG is supplying $3.91 \mathrm{~kW}$ real power to the load. The PMBLDC based wind generator, solar PV-array and BESS are supplying the 2.24 $\mathrm{kW}$ power to AC side (to load side) through VSC to compensate the remaining real power demand of the load.

Published By:

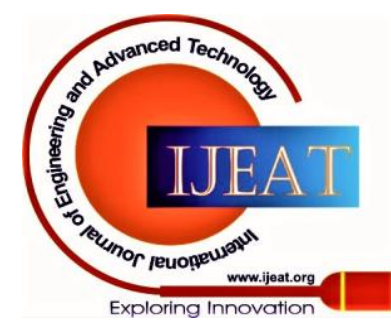




\section{Voltage Regulation of Hydro Standalone 1- $\Phi$ Micro Grid using Fuzzy Logic Based Adaptive Sliding Mode Control Algorithm}

The VSC converts the DC power generated by the remaining two renewable energy sources (solar PV-array and PMBLDC generator) and BESS into adjustable singlephase AC power when the SEIG output power is not sufficient to meet the power demand of the load. The power generated by solar PV-array and wind driven PMBLDC generator are demonstrated in Figs. 4(c) and 4(f) respectively. The PMBLDC generator and solar PV array generate total $1.8 \mathrm{~kW}$ real power, which is fed to the load through the VSC. In addition to it, an additional real power of $843 \mathrm{~W}$, needed to compensate the real power demand of the system is supplied by the BESS in order to control the system frequency through power balance mechanism of the proposed control algorithm. When the SEIG output power is less than or equal to the power demanded by the load, the power generated from the SEIG is directly fed to the load without any interference of the VSC. Figs. 4(a) to 4(l) show the power balancing ability of the proposed control algorithm. The proposed algorithm controls the VSC such that it balances the flow of power among the various energy sources (SEIG, PMBLDC generator, solar PV-array and BESS), which in turn controls the system frequency of the microgrid system. The VSC supplies 2.96 kVAR fundamental reactive power and harmonic in order to maintain constant voltage and to mitigate the harmonic currents injected due to nonlinear loads. In addition to other multiple functions, the VSC is improving power quality and power factor. Figs. 4(i) and 4(j) demonstrate the load current and VSC current waveforms respectively. The harmonic spectrum and THD of the SEIG output current shown in Fig. 4(k) indicates a THD of 3.8\%, while it is feeding a highly nonlinear load current of $31 \%$ THD as shown in Fig. 4(l). It proves the harmonics mitigation ability of the proposed control, as proposed control algorithm is satisfying the IEEE 519 standard of the power quality. The maximum power point tracking performance of the MPPT system used to extract the maximum power form solar PVarray, is shown in Fig. 5. The MPPT transfers $1.14357 \mathrm{~kW}$ power out of $1.15512 \mathrm{~kW}$ generated power from solar PVarray with the $99.99 \%$ MPP (maximum power point).

\section{B. Dynamic Performance of Proposed Microgrid}

The effect of change in insolation level and step change in wind speed and load are taken into consideration to verify the dynamic performance of the proposed control.

\section{1) Dynamic Performance of Proposed Microgrid at a Step Change in Solar Insolation Level}

The response of microgrid following a step increase in solar insolation level is demonstrated in Figs. 6(a) and 6(b). The response of the system following a step decrease in solar insolation level is shown in Fig. 6(c). A step increase in solar PV-array output current (channel 3 of result shown in Fig. 6(a)) has been observed while the system is following a step increase in insolation level. Test results (Figs. 6(a) to 6(b)) show that in response to this step increase in solar PVarray output current, the controller increases the charging current of the battery to divert the surplus generated power to BESS in order to control the system frequency. The dynamic performance of SEIG current is shown in Fig. 6(a), while the system is following a step increase in insolation level. Fig. 6(a) shows that the step change in solar insolation level does not cause any change or disturbance in the system voltage and SEIG current. It proves that proposed controller maintains the power balance under a dynamic situation arose due to step increase in solar insolation level which in turn increases the solar PV-array output current. The total generated power from all three renewable sources (microhydro, wind and solar PV array) becomes more than load. Therefore, surplus power is diverted to the battery in order to control the system frequency. Fig. 6(a) demonstrates the directional change of the battery current from discharging to charging mode in response to a step increase in solar PVarray output current. This balance of power among the various energy sources is achieved using frequency control loop of the proposed ASMC algorithm.

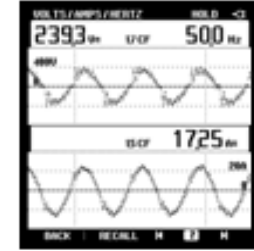

(a)

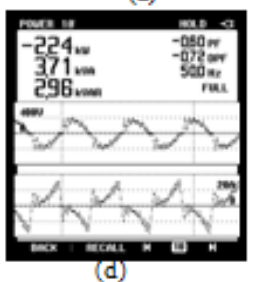

(d)

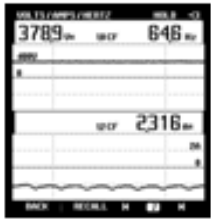

(e)

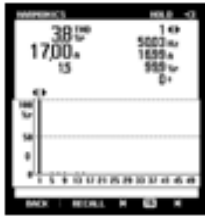

(h)

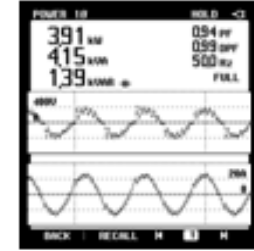

(b)

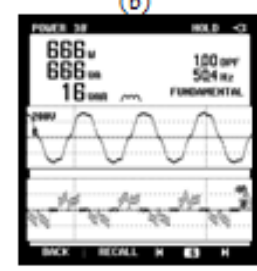

(e)

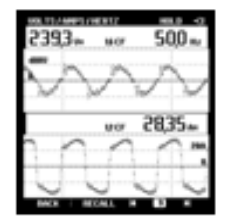

(f)

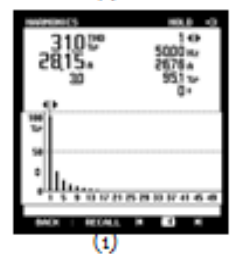

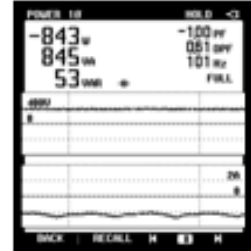

(c)

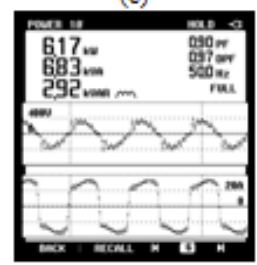

(f)

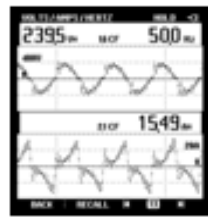

(g)
Fig. 4 Steady state performance of system when total generated power by all renewable sources (SEIG, PMBLDC generator and solar PV-array) is less than the load

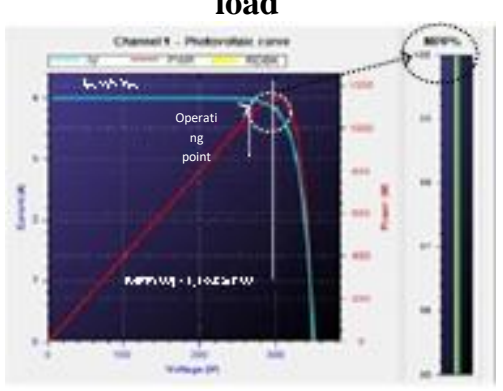

Fig. 5 Test performance of MPPT

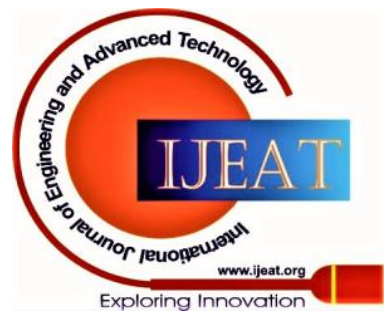




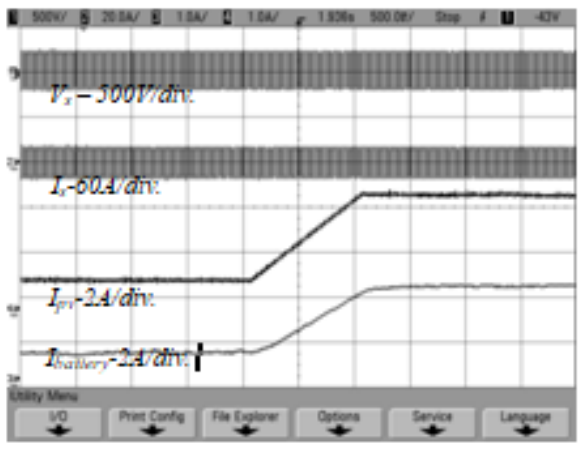

Fig. 6(a) Dynamic performance of the Vs, is, Ipv and Ibattery,, while the system is following a step increase in insolation level

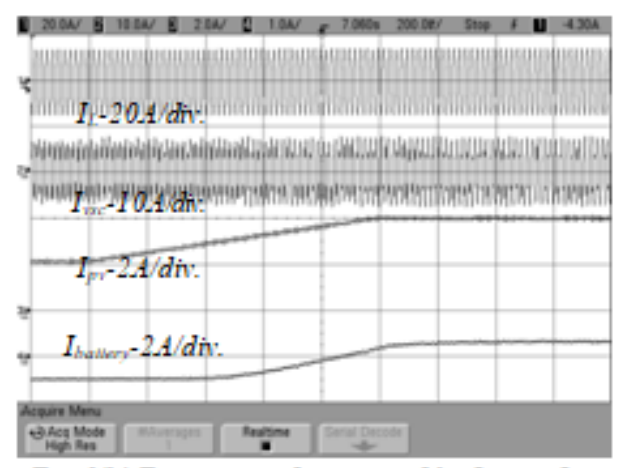

Fig. 6(b) Dynamic performance of the IL, iVSC, Ipv and Ibattery, while the system is following a step increase in insolation level

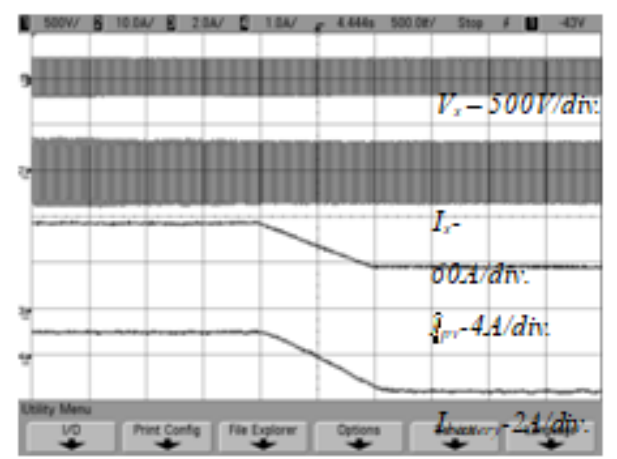

Fig. 6(c) Dynamic performance of the Vs, is, Ipv and Ibattery, while the system is following a step decrease in insolation level

The step increase in insolation level does not cause any disturbance or change in load current, as demonstrated in Fig. 6(b). The dynamic performance of the system voltage, SEIG current, solar PV-array current and battery current while the system is following a step decrease in insolation level, are demonstrated in Fig. 6(c). It is observed from test results shown in Figs. 6(c) that the step decrease in insolation level causes a decrease the solar PV-array current with the same slope and it subsequently decreases the battery current but it does not disturb the system AC voltage, load current or system frequency. The battery current goes from charging to discharging mode in order to regain the power balance in the system as shown in Fig. 6(c). Test results show that the system frequency and voltage are maintained constant during this dynamic condition.

\section{2) Dynamic Performance of Microgrid, Under a Step Change in Wind Speed}

The effect of a step change in the wind speed and consumer load on various other power quality parameters like system voltage, frequency, VSC current and load current, is considered to evaluate the dynamic performance of proposed microgrid. The response of the system following a step increase in wind speed is demonstrated in Figs. 7(a) and 7(b).The response of the system following a step decrease in wind speed is depicted in Fig. 7(c). The dynamic response of load current, VSC current, PMBLDC generator current and battery charging current are shown in Fig. 7(a) while the system is following a step change in wind speed. A step increase in PMBLDC generator current is observed in Fig. 7(a) while microgrid is following a step increase in wind speed. Test results shown in Fig. 7(a) to Fig. 7(b) show the system response to step increase in wind speed. The controller increases the battery charging current to divert the surplus generated power to the battery in order to control the system frequency. The dynamic response of system AC voltage, SEIG current, PMBLDC generator current and battery current while the system following a step decrease in wind speed, is demonstrated in Fig. 7(c). A step decrease in PMBLDC generator current (in response to the step decrease in wind speed) does not cause any disturbance in the SEIG current and system AC voltage as shown in Fig. 7(c).Test results shown in Figs. 7(a) and 7(b) show that total generated power from all three renewable sources (microhydro, wind and solar PV

array) becomes more than that of load, while the system is following a step increase in wind speed. Therefore, battery charging current increases to divert surplus power to the battery in order to control the system frequency. Fig. 7(b) demonstrates the directional change of battery current from discharging to charging mode in response to a step increase in PMBLDC generator current. This balance of power among the various energy sources is achieved using frequency loop of the control algorithm. The step increase in wind speed and PMBLDC generator current does not cause any disturbance or change in load current, as demonstrated in Fig. 7(a). It can be observed from test results shown in Fig. 7(c) that a step decrease in wind speed causes a decrease in the PMBLDC output current with the same slope and it subsequently decreases the battery current. While system is following a step decrease in wind speed, the battery enters discharging mode from charging mode in order to regain the power balance in the system as shown in Fig. 7(c). A step decrease in wind speed does not disturb the power quality parameters of the microgrid such as system frequency and voltage. It also does not cause any variation in the SEIG output current and load current. It can be clearly observed from Fig. 7(c) that the BESS entering the discharging mode from the charging mode in response to a step decrease in wind speed to control the system frequency and to maintain the balance of power among various generators and BESS.

Published By:

Blue Eyes Intelligence Engineering

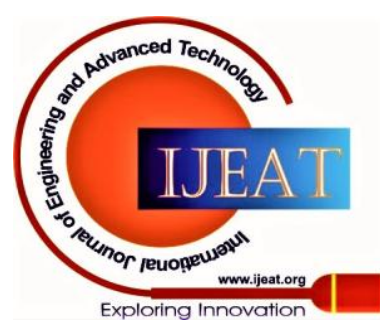




\section{Control Algorithm}

A step decrease in wind speed does not disturb the power quality parameters of the microgrid such as system frequency, voltage and THD. It also does not cause any fluctuation in the SEIG voltage, current and load current. Test results shown in Figs. 7(a) to 7(c) prove the ability of the proposed control algorithm to balance the power among the various sections of the system while the wind speed is fluctuating.

3) Dynamic Performance of the Microgrid, While it

Following a Step Change in Load

The dynamic response of the load current, VSC current, SEIG output voltage and system frequency while system is following a step change in load is demonstrated in Fig. 8. In this dynamic condition, the proposed control re-estimates the revised harmonic and fundamental reactive power need of the SEIG and load as well as active power need of the load with an excellent dynamic response.

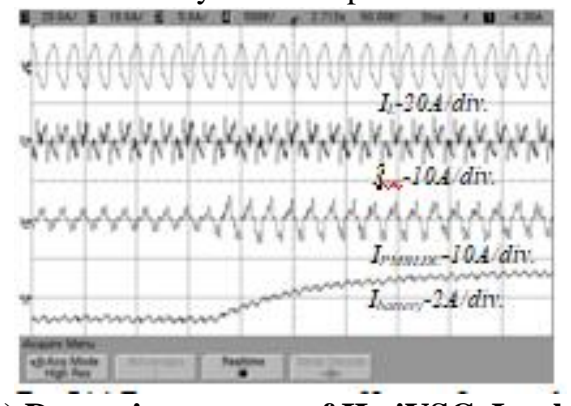

Fig. 7(a) Dynamic response of Ï̈, iVsí, Ipmbldc and Ibattery, while the system is following a step increase in wind speed

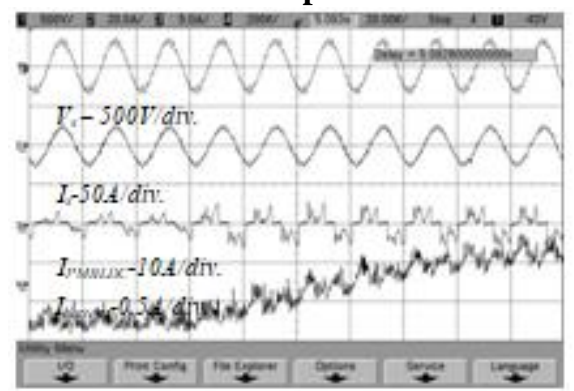

Fig. 7(b) Dynamic response of Vs, is, iPMBLDC and ibattery, while the system is following a step increase in wind speed

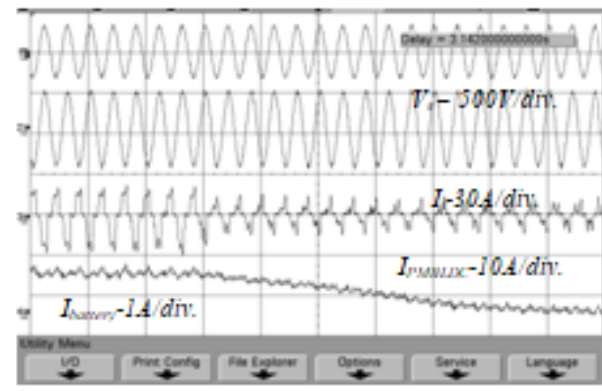

Fig. 7(c) Dynamic response of Vs, is, PMBLDC and battery, while the system is following a step decrease in wind speed

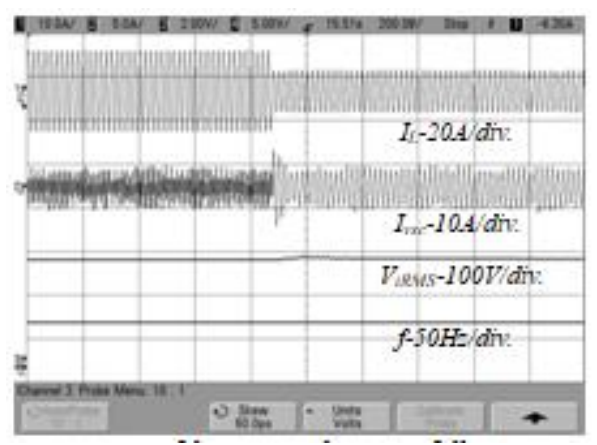

Fig. 8 Dynamic response of the proposed system, following a step change in wind speed and load Here the control revises the switching pattern for VSC to compensate the new reactive and active powers need of the system in order to regulate system voltage and frequency, respectively. Fig. 8 shows that microgrid voltage and frequency are restored to their rated value immediately in response to sudden change in load.

\section{CONCLUSIONS}

The adaptive sliding mode control algorithm for voltage and frequency control of standalone single-phase microgrid has been implemented in real time using DSP controller. The proposed SEIG based standalone microgrid has integrated three main renewable sources including microhydro, solar PV, and wind energy. Test results have proven that the ASMC algorithm has been effective and has good control of the microgrid voltage and frequency. The proposed control algorithm has also improved the power quality of the microgrid under linear and nonlinear loads and also ensures the optimum utilization of BESS and renewable energy sources.

\section{REFERENCES}

1. P. Dondi, D. Bayoumi, C. Haederli, D. Julian, and M. Suter, "Network integration of distributed power generation," J. of Power Sources, vol.106, no. 1-2, pp. 1-9, 2002.

2. J. P. Lopes, N. Hatziargyriou, J. Mutale, P. Djapic, and N. Jenkins, "Integrating distributed generation into electric power systems: A review of drivers, challenges and opportunities," Electric Power Syst. Research, vol. 77, no. 9, pp. 1189-1203, 2007.

3. N. Hatziargyriou, H. Asano, R. Iravani, and C. Marnay, "Microgrids, “IEEE Power Energy Mag.,” vol. 5, no. 4, pp. 78-94, Jul./Aug. 2007.

4. N. Ruiz, I. Cobelo, and J. Oyarzabal, "A direct load control model for virtual power plant management," IEEE Trans. Power Syst., vol 24,no. 2, pp. 959-966, May 2009.

5. H. Morais, P. Kádár, M. Cardoso, Z. A. Vale, and H. Khodr, "VPP operating in the isolated grid," in Proc. IEEE Power and Energy Soc. General Meet., 2008, pp. 1-6.

6. D. Pudjianto, C. Ramsay, and G. Strbac, "Virtual power plant and system integration of distributed energy resources," IET Renew. Power Gener., vol. 1, no. 1, pp. 10-16, Mar. 2007.

7. A. Molderink, V. Bakker, M. G. C. Bosman, J. L. Hurink, and G. J. M. Smit, "Management and control of domestic smart grid technology,” IEEE Trans. Smart Grid, vol. 1, pp. 109-119, Sep. 2010.

8. D. Pudjianto, C. Ramsay, and G. Starbac, "Microgrids and virtual power plants: Concepts to support the integration of distributed energy resources," in Proc. Inst. Mech. Engineers, Part A: J. Power and Energy (IMechE), 2008, vol. 222, pp. 731-741.

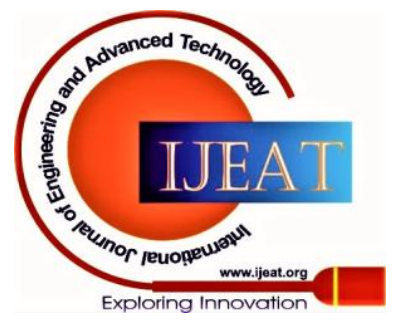


9. H. Karimi, H. Nikkhajoei, and M. R. Iravani, "Control of an electronically-coupled distributed resource unit subsequent to an islanding event," IEEE Trans. Power Del., vol. 23, no. 1, pp. 493501, Jan.2008.

10. F. Katiraei, M. R. Iravani, and P. W. Lehn, "Micro-grid autonomous operation during and subsequent to islanding process," IEEE Trans. Power Del., vol. 20, no. 1, pp. 248-257, Jan. 2005.

11. IEEE Standard for Interconnecting Distributed Resources with Electric Power Systems, 2003, IEEE Std. 1547.

12. R. Zamora and A. K. Srivastava, "Controls for microgrids with storage: Review, challenges, and research needs," Renewable and Sustainable Energy Reviews, vol. 14, no. 7, pp. 2009-2018, Sep. 2010.

13. A. Hajimiragha and M. R. D. Zadeh, "Practical aspects of storage modeling in the framework of microgrid real-time optimal control," in Proc. IET Conf. on Renewable Power Generat. (RPG), Sep. 2011, pp. 93-98.

14. F. Blaabjerg, R. Teodorescu, M. Liserre, and A. V. Timbus, "Overview of control and grid synchronization for distributed power generation systems,” IEEE Trans. Ind. Electron., vol. 53, no. 5, pp. 1398-1409, Oct. 2006.

15. A. Timbus, M. Liserre, R. Teodorescu, P. Rodriguez, and F. Blaabjerg, "Evaluation of current controllers for distributed power generation systems," IEEE Trans. Power Elect., vol. 24, no. 3, pp. 654-664, Mar. 2009.

16. J. Rocabert, A. Luna, F. Blaabjerg, and P. Rodríguez, "Control of power converters in AC microgrids," IEEE Trans. Power Electron., vol. 27, no. 11, pp. 4734-4749, Nov. 2012.

17. Claudio A. Cañizares and Rodrigo Palma-Behnke, "Trends in Microgrid Control,” IEEE Trans. Smart Grid, vol. 5, no. 4, pp. 19051919, July 2014.

18. U. K. Kalla, B. Singh and S. S. Murthy, "Normalised adaptive linear element-based control of single-phase self excited induction generator feeding fluctuating loads," in IET Power Electronics, vol. 7, no. 8, pp. 2151-2160, August 2014.

19. U. K. Kalla, B. Singh and S. S. Murthy, "Enhanced Power Generation From Two-Winding Single-Phase SEIG Using LMDT-Based Decoupled Voltage and Frequency Control," in IEEE Transactions on Industrial Electronics, vol. 62, no. 11, pp. 6934-6943, Nov. 2015.

20. S. Gao, G. Bhuvaneswari, S. S. Murthy and U. Kalla, "Efficient voltage regulation scheme for three-phase self-excited induction generator feeding single-phase load in remote locations," in IET Renewable Power Generation, vol. 8, no. 2, pp. 100-108, March 2014.

\section{AUTHORS PROFILE}

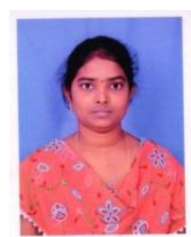

Mrs. Ramya Vasamsetti, Graduated from Aditya Engineering College, Surampalem. She is presently pursuing M.Tech in the Department of Electrical and Electronics Engineering, Pragati Engineering College, Surampalem, Peddapuram. Her Research areas include Renewable Energy Systems and Energy Storage Systems

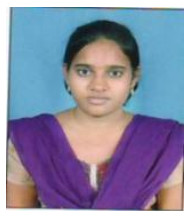

Ms. S.Varalakshmi, Post Graduated from Kakinada Institute of Engineering and Technology, Ramachandrapuram. She is currently working as Assistant Professor in the Department of Electrical and Electronics Engineering in Pragati Engineering College, Surampalem, Peddapuram.

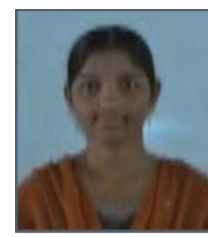

Mrs. M.Manga Lakshmi, currently working as Assistant Professor in the Department of Electrical and Electronics Engineering College in Pragati Engineering College, Surampalem, Peddapuram. She had Published 2 research papers in Inter National Journals. Her Research areas are Power Electronics and Network Theory. She has IAENG Membership

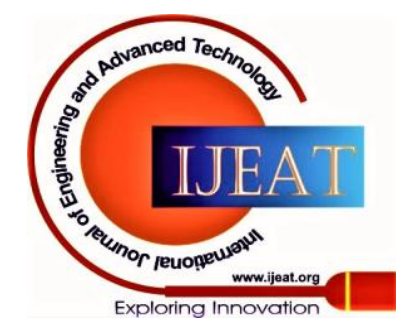

